\title{
Formation of the Creative Cluster of the Republic of Crimea: The Reality and Potential
}

\author{
Alexey Baranov ${ }^{1, *}$ Olga Kotlyarova ${ }^{2}$ Alexey Tagaev ${ }^{1}$ Aleksej Lesnik ${ }^{3}$ \\ ${ }^{1}$ South Russian Institute of Management - Branch of RANEPA, Rostov-on-Don, 344002, Russia \\ ${ }^{2}$ Vladimir branch of RANEPA, Vladimir 600017, Russia \\ ${ }^{3}$ European Institute of Applied Science and Management, Praha 818200 Czech Republic \\ *Corresponding author. Email: bav.skags@gmail.com
}

\begin{abstract}
In the presented article, the author's team analyzes the system components that form the creative cluster of the Republic of Crimea. The review of modern research works on the creative industry is analyzed. The practical part of the article is based on the data of numerous surveys, as well as on the results of strategic foresight sessions held with active and potential participants in the creative cluster of the Republic of Crimea in 2018. The authors proposed a system of measures that optimizes the development of the creative sphere of the region.
\end{abstract}

Keywords: creative economy, creative cluster, regional potential, Republic of Crimea

\section{PROBLEM STATEMENT}

Recent studies in the economic sphere indicate that the industry of impressions is becoming the engine of the regions, determined by the demand for unique products of human creativity and regulated by competent state policy. Emotional impressions as economic proposals occupy a leading position after raw materials, goods and services. Impressions are formed in the creative industry, which, in turn, is becoming one of the main sectors of world trade. Over the past decade, the volume of creative industries has doubled ( $\$ 500$ billion in 2015). It is important to note that not only the volume is growing, but also the intensity of the development of the creative sphere of the economy. Despite the fact that the share of creative industries in the Russian experience is insignificant (cf.: Russia - 0.3\%, China $32 \%$ ) and so far is based on the promotion of publishing products and design, creative industries, subject to a systematic development, can act as a driver of modern economics. In this regard, the formation of a creative economy is becoming a key tool for developing the economic potential of the region. A creative cluster does not simply imply the emergence of yet another new sector of the economy, its dynamism and creative foundation entail fundamental structural changes. It is significant that under the condition of targeted state influence and a systemically formed strategy at the level of a particular region, the development of a creative cluster will become a key factor in the region's competitiveness and economic growth.

\section{ANALYSIS OF RECENT PUBLICATIONS}

Recent studies of the creative economy in Russia can conditionally be differentiated in the following areas.
1) The specifics and multifactor development of the creative economy in Russia are studied in the works of E.R. Khakimova [8]; Hestanova R. [9].

2) Changes in the urban environment in the process of developing a creative cluster and the influence of millionplus cities on the general economic situation in the country are investigated in the works of T.V. Ashutovoi, D.Yu. Zhelnina [1]; A.S. Lavrinenko [5].

3) Human resource as the main potential of a creative cluster and the importance of educating and supporting professionals in the creative industry are considered in the works of V.Yu. Kombarova [3]; M. Kuleva [4].

In the framework of our study, creativity is defined as "a property of complexly organized systems of relations" [2: 5]. In this regard, the emergence of a new term creative economy is logical. The use of this term in foreign studies was first noted in a magazine in the journal Business Week in the publication "The 21st Century Corporation: The Creative Economy" [11]. John Hawkins calls the active implementation of intellectual creative resources as the most significant aspect in the described process [10:10]. The significance of the human resource as a source of innovative managerial decisions in any areas of human life comes to the fore (for more details see: [7: 13]).

From the perspective of the study, the concept of creative economy is logical to understand the system of socioeconomic relations, which allows using innovative knowledge and competencies to solve urgent socioeconomic problems. Such a system is interdependent with production based on non-borrowed ideas [6: 104]. Another contextually synonymous term is the concept of creative industries [cpractices.ru].

A creative economy is formed through the development of a creative cluster, which is understood as the systemic interconnection of creative independent companies within the framework of a national or regional economy. The relationship is due to the use of innovative creative ideas 
as the main factor of production, allowing to implement a strategy that provides an effective solution to the socioeconomic problems of the territory based on new knowledge.

The concept of a creative cluster at the international level was categorically defined by Simon Evans, moderating UNESCO's "Creative Cities" project. He defines the creative cluster as a community of creativity-oriented entrepreneurs operating in a closed area [en.unesco.org].

It should be noted that research and analytical activities aimed at studying the experience and prospects for the development of creative clusters are conducted both by international specialized organizations of the United Nations represented by UNCTAD, WIPO and UNESCO, as well as a number of large centers. Let us single out, for example, the British agencies Comedia and EUCLID; National Science, Technology, and Arts Foundation (NESTA, London); Queensland University of Technology (QUT, Australia); International Center for Social and Economic Research "Leontief Center" (St. Petersburg); Center for the Development of Creative Industries (St. Petersburg); Agency "Creative Industries" (Moscow); Calvert Forum international project (St. Petersburg) and others.

Interest in the development of the creative cluster is supported by economic prospects. It is significant that creative spheres stimulate the global economy and make up 3\% of world GDP, providing jobs for 29.5 million people ( $1 \%$ of the total world active population). According to a study presented in December 2015 at the International Confederation of the Society of Authors and Composers (CISAC) together with UNESCO, income from creative industries exceeds income from telecommunications services and creates more jobs than the automotive industry in Europe, Japan and the USA (29.5 million against 25 million) [www .gov.spb.ru].

The capitalization of creative industries in the world amounts to almost 2.3 trillion US dollars [www.kommersant.ru]. We can say that the creative cluster is becoming a trend characteristic of both developed and developing countries, which consider creative clusters as an integral element in the development of a new digital economy.

The percentage of global income from the development of the creative cluster, as well as people employed in the creative sphere in different regions of the world, is presented in Table 1.

\section{PURPOSE AND OBJECTIVES}

The purpose of this article is to formulate a development strategy for the creative cluster of the Republic of Crimea. The main research tasks include: 1) a conceptual analysis of the development of the creative industry of the Republic of Crimea; 2) the identification of aspects that negatively affect the development of the creative cluster of the region; 3 ) implementation of the results of the strategic session in the creation of a development strategy.
Table 1. World Creative Cluster

\begin{tabular}{|c|c|c|c|}
\hline Region & $\begin{array}{c}\text { \% of global } \\
\text { income from } \\
\text { creative } \\
\text { industries }\end{array}$ & $\begin{array}{l}\% \text { of } \\
\text { jobs }\end{array}$ & Prevailing direction \\
\hline Asia Pacific & $33 \%$ & $43 \%$ & $\begin{array}{c}\text { Game Industry, } \\
\text { Publishing }\end{array}$ \\
\hline Europe & $32 \%$ & $26 \%$ & $\begin{array}{c}\text { Historical heritage } \\
\text { and others }\end{array}$ \\
\hline North America & $28 \%$ & $16 \%$ & $\begin{array}{c}\text { Cinema, television, } \\
\text { performing arts, } \\
\text { digital content } \\
\text { creation. }\end{array}$ \\
\hline $\begin{array}{c}\text { Latin America, } \\
\text { the Caribbean }\end{array}$ & $6 \%$ & $7 \%$ & $\begin{array}{c}\text { Television, mass } \\
\text { media. }\end{array}$ \\
\hline $\begin{array}{c}\text { Africa and the } \\
\text { Middle East }\end{array}$ & $3 \%$ & $8 \%$ & Music \\
\hline
\end{tabular}

\section{ANALYSIS OF THE CREATIVE POTENTIAL OF THE REPUBLIC OF CRIMEA.}

\subsection{The results of a sociological survey.}

One of the foundations for creating a development strategy for the creative cluster of the Republic of Crimea was the results of strategic sessions and opinion polls.

Holding strategic sessions allowed us to systematically present a list of the largest subjects of the creative sphere of the Republic of Crimea and to model a description of the creative economy. It should be noted that building a development strategy for the creative cluster of the Republic of Crimea based on taking into account not only the existing situation, but also transformational prospects, significantly increases the adaptability and feasibility of the developed strategy.

It should be noted that building a development strategy for the creative cluster of the Republic of Crimea based on taking into account not only the existing situation, but also transformational prospects, significantly increases the adaptability and feasibility of the developed strategy.

The authors conducted a sociological study. The sample of respondents was 243 participants in the creative industry of the Republic of Crimea. To evaluate the respondents, the following creative industries were proposed: music and music production; cinema and multi-industry; fashion; museum work and preservation of cultural heritage sites; design; architecture; visual arts; performing arts; publishing; new media; folk arts and crafts; gastronomic culture.

The results of the survey on the level of development of the creative economy of the Republic of Crimea are presented in Fig. 1. 


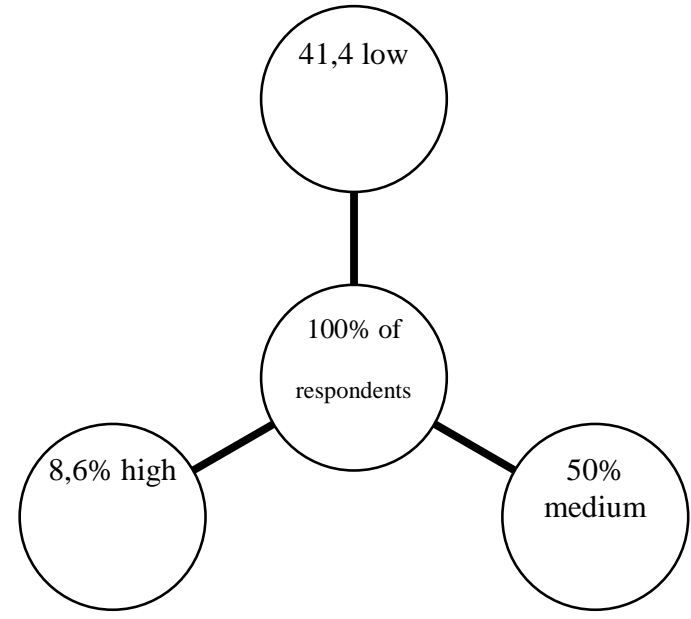

Figure 1. The level of development of the creative sphere of the Republic of Crimea

It is significant that $14 \%$ of respondents recognized soft loans and tax preferences as actual measures of economic support for the creative sphere.

Also, in the course of a sociological study, an urgent need was found for educational programs that form competencies in the fields of the creative economy, $8 \%$ of respondents confirmed this request.

\subsection{Analysis of the potential of organizations involved in a creative regional economy.}

The authors analyzed the potential of organizations and institutions conducting economic activity in the territory of the Republic of Crimea. Their total number is 33,465 units as of $01 / 01 / 2018$. The quantitative indicator has a positive trend and exceeds the indicator of the same period in 2017 by $2.7 \%$.

The share of organizations that form the creative economy of Crimea is $20.3 \%$ (6,793 enterprises). Based on up-todate statistical reporting, creative areas included the activities of cafes, restaurants, catering establishments, hotels, information and communication activities, professional, scientific and technical activities, education, activities in the field of culture, sports and leisure and entertainment.

In comparison with 2017, in 2018, for each of these types of activities, an increase in the quantitative indicator of involved entrepreneurs is observed. The leader is a subcluster of organizations of professional, scientific and technical activities, the number of which has grown by $3 \%$, which is higher than the growth rate of the total number of enterprises (1.2\%). In second place is the activity in the field of information and communication with an indicator of $1.9 \%$.

The volume of paid services in the discussed areas of activity provided to the population amounted to 12.9 million rubles. or $20 \%$ of the total volume of paid services. The average number of employees involved in the respective activities is $25 \%$ of the total working population, that is 102,242 people.

The share of organizations that form the spectrum of innovatively active entities and implement technological, organizational, marketing innovations is $2.8 \%$, that is, 190 enterprises following the results of 2016. In the total number of employees involved in the regional economy, the percentage of personnel engaged in research and development is $0.3 \%$, that is, 308 employees.

From all the above, we conclude that the formed and largescale potential for the development of the creative economy of the Republic of Crimea is in terms of the number of enterprises involved and the number of employees in the creative sphere.

\subsection{The creative potential of Crimea in terms of cultural heritage.}

A positive factor in creative development is the significant position of Crimea among other regions of the Russian Federation in terms of the number of cultural heritage sites. Data on the cultural heritage of the Republic of Crimea for 2018 is presented in Table 2.

Table 2 Data on monuments of local and national significance of the Republic of Crimea for 2018.

\begin{tabular}{|l|l|}
\hline \multicolumn{1}{|c|}{ Value Scale } & \multicolumn{1}{c|}{ Quantity } \\
\hline Federal level & 218 objects \\
\hline Regional level & 1806 objects \\
\hline $\begin{array}{l}\text { Revealed archaeological } \\
\text { heritage }\end{array}$ & 2185 sites \\
\hline Revealed cultural heritage & 285 objects \\
\hline
\end{tabular}

The total number of cultural heritage objects of the Republic of Crimea of regional and federal significance, as well as the number of identified objects is 4498 .

Note regional differences in the territorial distribution of existing facilities. So, monuments of monumental art are an important component of the northern regions of Crimea and expand the potential tourist Bakhchisarai district (59\%), Yevpatoria (72.2\%), Kerch (77.9\%), Simferopol (46.4\%) and Yalta (38.8\%).

In our opinion, state and municipal cultural institutions are an integral part of the creative regional industry, providing the population and guests of Crimea with a wide range of cultural, educational and information services. These services are aimed at satisfying the aesthetic needs of residents of the republic and contribute to the creation of a higher quality of life.

According to 2018 data, more than 1,400 cultural and art institutions are functioning in the Republic of Crimea, including: 663 library institutions (4 of which are republican); 35 museum institutions; 4 theaters; 1 concert organization; 1 circus; 79 movie theater facilities; 3 republican educational institutions; 65 children's art schools [mkult.rk.gov.ru]. 
Note the uneven distribution of cultural institutions in cities and rural areas. Municipal districts, unlike urban districts, demonstrate a higher level of provision with a library fund and the number of places in club institutions [mkult.rk.gov.ru].

\subsection{Factors for the development of creative infrastructure.}

One of the key conditions for the development of a creative cluster in Crimea is the creation of an infrastructure for its functioning. In this regard, in the course of the study, factors were identified that made it possible to effectively develop the infrastructural support of the creative cluster. We will name the most significant of them.

1. The formation of creative spaces in the format of creative quarters, parks, place-sharing, redevelopment.

2. The formation of zones of free access to the Internet in the territories of creative spaces.

3. Formation of "points" for the development of creative competencies on the basis of educational organizations and creative spaces.

4. Creation of intercluster incubators, accelerators, fablabs, collective use centers and CMITs, technology parks, venture capital funds, coworking, anticafe based on creative spaces.

5. Development of creative "events with a common agenda" for all areas of the creative economy of the territory.

In the framework of solving the problem of attracting and preserving the maximum number of cultural heritage objects, as well as for organizing rational tourism activities around them, it is proposed to pay attention to the problem of low level of information openness.

\subsection{Results of the strategic session.}

The practical part of the proposed work is based on the results of a strategic session aimed at developing a development strategy for the Crimean creative cluster.

The strategic session involved participating organizations representing the creative industry cluster, representatives of the executive authorities of the Russian Federation and the Republic of Crimea, as well as other interested parties. The session program was implemented in two stages. At the initial stage, a discussion was held on 1) the prospects for the development of the cluster; 2) the presence of interested parties; 3) the uniqueness of the cluster and its product line; 4) the boundaries of the project itself; 5) preliminary SWOT analysis. The final stage included a discussion of the results of developing a cluster strategy for the creative industry of the Republic of Crimea, as well as the future organizational structure of the cluster and long-term development priorities.

The experts present were randomly divided into 4 groups. Among the participants were government officials, representatives of the education system, and entrepreneurs.
The expert group was invited to form the image of the future of Crimea in 2030. As the main elements of the creative sphere were named:

- development of an accessible environment,

- organization and structuring of event tourism,

- improving the environmental friendliness of transport,

- the formation and development of creative communities,

- the formation of a creative educational environment and its interdependence with employers,

- establishment of mini-production for small businesses (special attention was paid to the gastronomic sphere),

- the development of street art in residential areas of settlements,

- modernization of landscape design, taking into account Crimean climatic features,

- competent organization of intra-house territories, implying an individual approach,

- organization of health zones, sanatoriums and dispensaries,

- structuring visual frames in a single architectural style, - creation of platforms for free and individual creativity.

The next stage of the session involved the development and analysis of the characteristics of a creative cluster, its criteria and resources. The main characteristics of the creative cluster were identified as 1) formats of interaction between subjects of the cluster creative economy; 2) creative human capital; 3) cultural and recreational capital. The next stage of work was the formulation of threats, risks or barriers that impede the creative development of the region. The expert groups identified 19 points among which: 1) the lack of cultural and educational level of the population; 2) environmental degradation; 3) underestimated motivational activity of participants; 4) the inability to predict changes from the point of view of the personnel of the leadership in the system of state and municipal services; 5) the inability to bypass bureaucratic procedures; 6) corruption in the system of state and municipal government; 7) lack of foreign specialists; 8) a lack of representatives of the state and municipal service of knowledge in the field of creative industries; 9) slow creative thinking of the population of the Republic; 10) insufficient venture capital; 11) lack of startup platforms; 12) sedentary, not labile formation; 13) lack of modern business technologies; 14) a low level of remuneration for specialists in a creative economy; 15) lack of developed road engineering infrastructure; 16) a high proportion of the shadow economy; 17) lack of creative sites, coworking, technology parks; 18) the high cost of tourism products; 19) the lack of readiness of cultural heritage sites for mass visits.

The experts compiled a list of real-life events that in the near future, until 2020, will be implemented with a view to regional creative development. Among them: 1) the creation of a working expert group in order to identify the competitive advantages of the leading branches of the creative economy of Crimea; 2) development of indicators for assessing the working group; 3) development and approval of an action plan for the development of the creative cluster of Crimea; 4) creating a forum and holding breakout sessions on sectors of the economy to identify 
best practices and study the experience of organizing a creative industry in Russia and abroad; 5) presentation of business projects for each industry requiring development; 6) identification of best practices and their replication; 7) the formation of a system of financial support for the implementation of projects and their administration; 8) participation in the implementation of government orders in the development of creative industries; 9) the formation of target places for higher education, as well as additional education in the leading universities of the country in the field of culture and art, creative management; 10) attracting NDP from leading universities of the country to programs, conducting master classes and trainings on the development of a creative economy.

\section{CONCLUSIONS}

We can confidently say that the creative cluster of the Republic of Crimea has prospects and priority areas for development, which include 1) a rich historical heritage; 2) gastronomy; 3) sport; 4) the development of cinema; 5) science and education; 6) music; art.

As the most formed areas, we note subclusters of the resort and recreation complex and the multinational heritage of Crimea.

However, in our opinion, special expert attention should be paid to procedural fears and expectations, among which: 1) the presence of a new and unfamiliar; 2) lack of clear goals and deadlines; 3) lack of information on the duration of the event; 4) lack of data on who and how the result will be used; 5) lack of formulation of the result itself.

Also, as limitations and threats that impede the achievement of the desired image of a creative cluster, we note the imperfection of the management system, bureaucracy; lack of funding for government agencies and projects; as well as the geopolitical situation.

Questions that remain open and debatable are: 1 ) who are the subjects of the creative cluster and what are the selection criteria; who can get resident status; 2) why becomes a member of the creative cluster; how to identify the motivation of the participants; 3) what potential participants are willing to "invest in" and what resources to use; 4) what expectations do participants have of participating in the development of a creative cluster; what result they expect; 5) what guarantees do the creative cluster have; what ensures the sustainability of its development; 6) what rules and norms of interaction are formed among participants in a creative cluster when interacting with each other; 7) what circumstances may interfere with a particular participant; what are the barriers to active participation.
In conclusion, we consider it necessary to focus on the innovativeness of the creative development of the region in terms of the rational use of human resources. Improving the system of creative regional development will not only improve the economic status of the Republic of Crimea, but also enrich the cultural level of the population.

\section{REFERENCES}

[1] Ashutova T.V., Zhelnina Z.Yu. The strategic project "Creative City - Territory of Development" as a model of interaction between the basic university and the region, Higher Education in Russia. 2019. № 3. P. 116-124.

[2] Belokrylova O.S., Dubskaya E.S. Creative Economy: Formation in the World and in Russia // Terra Economicus,2013, V. 11. №. 4. P. 5-1

[3] Kombarov V.Yu. The phenomenon of the subject of labour at industrial enterprises in Siberia: an analysis in a poststructuralist sociological perspective and the construction of a typology, 2015, № 3. P. 88-107.

[4] Kuleva M. "Put on a collar with electric current": young employees of the "New" and "Old" cultural institutions in the workplace, Journal of Social Policy Studies. № 2. P. 337-354.

[5] Lavrinenko A.S. Actual issues of state regulation of creative industries, Issues of public administration. 2015. № 4. P. 135-153.

[6] Stepanov A. A., Savina M. V. Creative economy: essence and problems of development, Management of economic systems. 2013. № 12. P 104-106.

[7] Florida R. Creative class: people who change the future, M .: Classic-XXI century. 2011.

[8] Khakimova E.R. Creative cluster as an element of the creative potential of the territory, Actual problems of economic sciences. 2013. № 34. P. 121-124.

[9] Hestanov R. Creative industries - development models, Sociological review. 2018. № 3. P. 173-196.

[10] Hawkins J. Creative economy. How to turn ideas into money, M .: Classic-XXI century. 2011. 